\title{
Curso de "Artes Práticas: Educação para o Lar" da Universidade Católica de Minas Gerais: rupturas e permanências na relação mulher, família e ensino na década de 1970
}

\author{
Liana Maria Reis* \\ Marina Gomes de Brito **
}

\begin{abstract}
Resumo
A década de 1970 foi marcada, no Brasil, por movimentos que buscavam romper com a "antiga moral", que levaram, entre outras coisas, a uma maior liberdade sexual, à inserção da mulher em segmentos até então dominados pelos homens, à escolarização em níveis cada vez mais avançado das mulheres e à legalização do divórcio. Nesse contexto, a Universidade Católica de Minas Gerais (UCMG) criou o curso de Artes Práticas: Educação para o Lar, que tinha por objetivo proporcionar uma formação acadêmica que permitisse às alunas cuidar do lar ou tornarem-se professoras. $\mathrm{O}$ presente artigo analisa o currículo do curso, a fim de identificar quais eram os valores subjacentes a ele e a qual parcela da sociedade o curso interessa.
\end{abstract}

Palavras chave: Permanências e rupturas; Década de 1970; Mulher; UCMG.

O presente artigo tem por objetivo analisar a situação da mulher, na década de 1970, a partir da análise do currículo do Curso de Artes Práticas: Educação para o Lar oferecido pela Universidade Católica de Minas Gerais (UCMG) entre os anos de 1973 e 1977.

O curso Artes Práticas integrava o Centro de Ciências Humanas juntamente com os cursos das licenciaturas (Letras, Ciências e Estudos Sociais) e oferecia duas formações: o de Educação para o Lar e o de Técnicas Comerciais. Esses cursos não prescindiam de uma formação acadêmica sob a tríade: ensino, pesquisa e extensão, sua ideia era, como indica o nome, a praticidade, uma formação acadêmica que proporcionasse as técnicas necessárias para ser uma boa dona de casa ou um bom vendedor.

\footnotetext{
* Doutora em História Social pela Universidade de São Paulo (USP), professora da Pontifícia Universidade Católica de Minas Gerais (PUC Minas).

** Bacharel Licenciada em História pela Pontifícia Universidade Católica de Minas Gerais.
} 
Sabendo-se que a Universidade tem por objetivo formar profissionais e cidadãos capazes de atender às necessidades da sociedade em que se inserem, surgem algumas questões, tais como: qual demanda o curso de Educação para o Lar pretendia atender? Quais os valores eram subjacentes ao currículo do curso?

Para obter tais informações torna-se profícua a análise dos currículos do curso, pois, como ressalta Elba Sá Barreto (2000):

\begin{abstract}
As orientações curriculares oficiais refletem também um ideário que permeia mais amplamente a sociedade através das suas instituições e das forças sociais que as animam, ideário esse que vai além da interpretação particular, que fazem os segmentos do poder, de certos princípios e pressupostos educacionais. Vêm, assim, tais orientações constituir, elas próprias, testemunhos que cristalizam, através de determinada versão, certos valores socialmente compartilhados. (BARRETO, 2000, p. 7).
\end{abstract}

Para análise da proposta, utilizaremos como fonte, os currículos do curso entre os anos de 1974 a $1977^{1}$, bem como os Relatórios de Atividade da PUC Minas ${ }^{2}$ do mesmo período, a fim de levantar os dados que possibilitem responder às questões suscitadas.

\title{
A mulher na década de 1970
}

Os anos de 1970 no Brasil são marcados como a década em que a Ditadura Militar atingiu seu auge e sua crise. No início da década, impulsionada pelos investimentos estrangeiros, a economia viveu um período de prosperidade econômica, que ficou conhecido como "milagre econômico". Entretanto, esse milagre atingiu apenas uma pequena parcela da população, como é o caso da classe média que passa a ter acesso a bens de consumo duráveis, atingindo uma situação de conforto (SILVA, 1990).

É também nessa década que o processo de urbanização, oriundo do crescimento e da consolidação do capitalismo no Brasil, atinge seu auge, passando a maior parte dos brasileiros a morar em cidades. Esse processo também se liga a uma mudança dos padrões de vida, a um crescimento dos manifestos que marcarão a crise da ditadura:

\footnotetext{
${ }^{1}$ O Centro de Memória e Pesquisa Histórica da PUC Minas guarda, em seu acervo, os cadernos com o currículo e o conteúdo programático do curso.

2 Os Relatórios de Atividades são publicações anuais da PUC Minas. Trazem dados que resumem as atividades realizadas pela instituição, portarias expedidas naquele ano, dados estatísticos, dentre outros, e podem ser consultados na Biblioteca Padre Alberto Antoniazzi.
} 
As metrópoles foram palco principal dos mais diversos movimentos sociais [...]. Depois de anos de silêncio, as ruas da cidade foram tomadas pelos mais diversos movimentos por liberdades e direitos: sindical, popular, dos estudantes, das mulheres, dos negros, dos homossexuais. (HABERT, 1996, p. 73).

Esses movimentos pretendem defender as chamadas "minorias", como é o caso das mulheres. A liberação sexual, a popularização da pílula anticoncepcional, criada na década anterior, e a inserção feminina cada vez mais ativa no mercado de trabalho são fatos interligados e que levam as mulheres a exigirem direitos iguais. Cumpre lembrar que a década de 1970 é marcada pela segunda leva do movimento feminista na América Latina (COSTA, 2005). Marco crucial para Ana Alice Costa são os eventos comemorativos do Ano Internacional da Mulher, em 1975, no qual foram realizadas várias discussões sobre o "novo movimento" em São Paulo, Rio de Janeiro e Belo Horizonte, sob o patrocínio da ONU (COSTA, 2005). A partir dessas discussões surgiram grupos de debates, movimentos reivindicatórios de creches, movimentos contra a violência, e discussões em relação à sexualidade:

\footnotetext{
O movimento feminista se proliferou través de novos grupos em todas as grandes cidades brasileiras e assume novas bandeiras como os direitos reprodutivos, o combate à violência contra a mulher, e a sexualidade. $\mathrm{O}$ feminismo chegou até a televisão revolucionando os programas femininos, nos quais agora, junto às tradicionais informações sobre culinária, moda, educação de filhos etc. apareciam temas até então impensáveis como sexualidade, orgasmo feminino, anticoncepção e violência doméstica. (COSTA, 2005, p. 14).
}

Além disso, amplia-se o debate acerca do casamento e de sua dissolução, o que leva à legalização do divórcio em 1977, embora com algumas restrições. Para Zélia Maria Biasoli-Alves, essas lutas e conquistas têm grande relação com o "direito de escolarização" que a mulher havia conquistado desde meados do século XIX. Segundo a autora, até esse momento, pensava-se que o estudo era considerado não só inútil para a moça, mas também prejudicial, pois a faria "sonhar com bobagens" (BIASOLI-ALVES, 2000), exceção feita à preparação para o magistério, dito como extensão natural do cuidado com os filhos. Com a vida se tornando cada vez mais urbana, a partir da década de 1950, a mulher passa a ter um papel cada vez maior na educação dos filhos e na gestão da casa, fazendo com que ela precisasse de conhecimentos além daqueles adquiridos com a mãe.

Ademais, sua participação no mercado de trabalho também se diferencia: 
De um lado, a mulher amplia sua presença nos níveis mais elevados de ensino, como produto de seu ingresso nas Universidades, embora persista a preponderância feminina maciça no nível elementar [...]. De outra parte, acentua-se a presença feminina em outras ocupações da força de trabalho, diminuindo relativamente a importância do magistério, que passa a ser suplantado, como ocupação de nível médio, pelas atividades burocráticas. (AMADO, 1998, p. 6).

Mas a situação da mulher na década de 1970 não é só de rupturas. Existem ainda continuidades das décadas anteriores, que são valores defendidos, principalmente, pela Família e pela Igreja que "pretendem continuar a dizer o que é certo e o que é errado, o que se pode considerar como um bom comportamento e o que é inaceitável para uma ‘moça de família"” (BIASOLI-ALVES, 2000, p. 237). Dessa forma, mesmo em meio às mudanças, essas instituições zelam no sentido de impedir grandes rupturas com a "antiga moral”, isto é, valores que faziam parte da identidade da geração anterior à década de 1970, mas que agora são questionados.

Nesse sentido, os estudos servem como uma possibilidade, no caso de o casamento não dar certo, de a mulher ter uma profissão:

[...] percebe-se uma "diminuição na rigidez das normas, um começo de encantamento com a inteligência, a competência, o trabalho e a independência da filha", resguardado o valor atribuído ao "casamento com a pessoa certa, a obediência a padrões de moralidade estabelecidos e mantidos através de gerações". Por exemplo, seria bom se ela tivesse algo com que se virar porque, hoje em dia, ninguém sabe [...] é tudo tão incerto [...] nem o casamento garante [...]. (BIASOLI-ALVES, 2000, p. 237. Grifo do autor).

Partindo desse pressuposto, mesmo o direito à educação, alcançado na década de 70, está ligado não a uma ruptura da função doméstica da mulher, mas à sua permanência ${ }^{3}$. Dessa forma, a mulher que é socialmente destinada ao lar, educa-se porque:

\footnotetext{
${ }^{3}$ O conceito de permanência está ligado ao de longa duração criado por Fernand Braudel. Segundo ele, "todo trabalho histórico decompõe o tempo decorrido, escolhe entre suas realidades cronológicas, segundo preferências e opções exclusivas, mais ou menos conscientes" (1978, p. 44). A partir dessa constatação, o autor divide o tempo histórico em três: o tempo breve, que é o tempo do fato, dos acontecimentos políticos; o tempo médio, aquele da nova história econômica e social, atenta aos ciclos econômicos, que tem duração de dez, vinte ou cinquenta anos; e, por fim, o tempo da longa e até longuíssima duração. Esse último é o tempo da relação do homem com o meio geográfico, das estruturas etc. É um tempo que muda tão devagar que chega a parecer imóvel, pois, em período grande de tempo, existem permanências (BRAUDEL, 1978, p. 44). Os valores morais podem ser analisados sob a perspectiva da longa duração, uma vez que muitos desses valores permanecem quase imutáveis por várias gerações.
} 
[...] percebe-se como importante que ela domine a leitura e a escrita de modo consciente. [...] Isto, não porque ela seja um sujeito de direitos e deva lhe ser assegurada a igualdade, mas porque se espera dela competências que melhor promovam a educação dos filhos e a própria vida doméstica, que façam dela o suporte adequado para o suporte profissional do seu esposo. (BIASOLIALVES, 2000, p. 236).

Em outras palavras, a mulher deve ser educada para ocupar seu lugar no lar, afinal, ela permanecia como responsável pela felicidade do marido, pela criação dos filhos dentro dos valores morais e cristãos da sociedade brasileira e como guardiã da paz doméstica e do equilíbrio conjugal (BASSANEZI, 1997).

\section{O curso de Artes Práticas: Educação para o Lar da Universidade Católica de}

\section{Minas Gerais}

É nesse contexto que o curso de Artes Práticas: Educação para o Lar da UCMG nasce. E a análise do currículo, como se verá a seguir, indica que sua intenção era a de preparar a mulher urbana, especialmente das camadas médias e dominantes, para assumir a casa, à medida que o marido se dedicava cada vez mais ao trabalho.

O curso de Artes Práticas foi oferecido nos vestibulares dos anos de 1973 a 1976, trazendo em seu currículo disciplinas que proporcionassem às alunas uma formação para a gestão doméstica e para a criação dos filhos. Tinha também algumas disciplinas da licenciatura, que as possibilitavam a ingressarem no magistério. No processo de domesticação da mulher, reafirmado ao longo do século XIX, a carreira profissional era incompatível com o casamento e com a maternidade. Entretanto, as moças solteiras, antes de contraírem matrimônios, poderiam exercer a função de ensinar, porque:

Dizia-se, ainda, que o magistério era próprio para as mulheres porque era próprio um trabalho de "um só turno", o que permitia que elas atendessem suas "obrigações domésticas" no outro período. Tal característica se constituiria em mais um argumento para justificar o salário reduzido supostamente, um salário complementar”. (LOURO, 1997, p. 453).

Aos argumentos religiosos e higienistas que responsabilizavam as mulheres pela manutenção de uma família saudável, juntaram-se aos "novos conhecimentos da psicologia, acentuando a privacidade familiar e o amor materno como indispensáveis ao desenvolvimento físico e emocional das crianças." (LOURO, 1997, p. 454). 
O curso de Artes Práticas foi formado no contexto da Reforma Universitária de 1969, que, dentre outras mudanças, instituiu o ensino semestral e a matrícula por disciplina. O curso tinha duração de cinco períodos, ou seja, de dois anos e meio. Nos primeiros períodos, as alunas deveriam cursar o chamado "Primeiro Ciclo", criado pela Reforma Universitária de 1969. O primeiro ciclo objetivava:

\footnotetext{
a) recuperação de insuficiências evidenciadas, pelo concurso vestibular, na formação (dos alunos);

b) orientação para escolha da carreira;

c) realização de estudos básicos para ciclos ulteriores. (Artigo 5, Decreto 464/69).
}

Nesse sentido, no primeiro período, os alunos da UCMG faziam quase as mesmas matérias, à exceção de algumas disciplinas voltadas para a recuperação de matérias específicas de determinadas áreas. As turmas eram, então, formadas por alunos de vários cursos. Em 1975, um novo projeto coloca em vigor, a partir do ano seguinte, o Ciclo Básico por área de conhecimento.

O primeiro período era composto, então, de disciplinas gerais, como, no caso dos cursos da área de Ciências Humanas, Iniciação Filosófica I ( Filosofia e Ciência), Iniciação Filosófica II (O mundo contemporâneo), Introdução aos Estudos Universitários, Psicologia, Sociologia e Português: Comunicação e Expressão.

No segundo período, iniciavam-se as disciplinas específicas do curso. No caso do curso de Educação para o Lar, algumas disciplinas são elucidativas do seu caráter. Através desse curso, a aluna aprenderia, no segundo e no terceiro períodos, questões acerca da moradia, promovida pelas disciplinas de Habitação I e Habitação II. Na primeira, das citadas disciplinas, como se lê nos conteúdos programáticos do curso (UNIVERSIDADE CATÓLICA DE MINAS GERAIS, 1974; 1975; 1976; 1977, s/n), a discussão seria feita em torno da questão habitacional como necessidade humana e como problema no Brasil, além de se iniciar os estudos sobre o planejamento habitacional. Mas a aquisição do imóvel era função do homem e cabia à mulher a sua organização. Nesse sentido, a disciplina de Habitação II trazia em seu conteúdo programático temas como composição visual e cores, para que a aluna pudesse, a partir da terceira unidade, aplicar os conceitos aprendidos na decoração da casa, no arranjo de flores, na seleção, no uso e na conservação de móveis e equipamentos da habitação. 
Cumpre lembrar que este lugar social da mulher, culturalmente, foi definido desde o período colonial brasileiro (PRIORE, 1993, p. 26-32) ${ }^{4}$.

Depois de uma casa bonita e bem organizada, a mulher precisaria cuidar de sua gestão. Para esse fim, era oferecida, no quarto período, a disciplina de Economia doméstica e atividade profissional relacionadas com a matéria. Nessa disciplina, o aluno deveria aprender algumas noções de economia e se educar enquanto consumidor. Nesse sentido, a quinta unidade da disciplina trazia os seguintes tópicos:

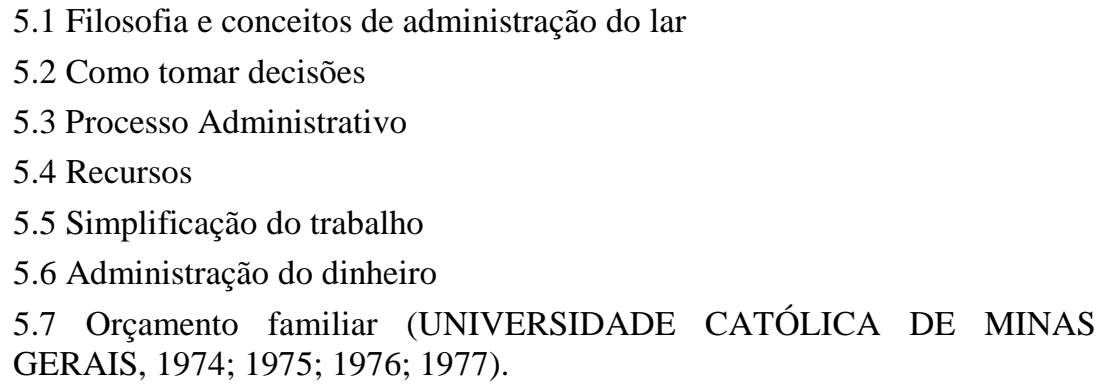

Com o marido no trabalho e passando cada vez um tempo menor em casa nessa vida moderna, a mulher precisa "tomar conta da casa". É ela quem deverá fazer as contas para suprir as necessidades alimentares, pagar as dívidas, etc. Dessa forma, o curso superior garantiria à mulher obter os conhecimentos necessários para que o marido pudesse trabalhar sem preocupar-se com as questões domésticas.

Mas, moça prendada que deveria ser, a aluna teria ainda as disciplinas de Vestuário I e Vestuário II, ofertadas no $2^{\circ}$ e $3^{\circ}$ períodos respectivamente, para que aprendesse tanto a cuidar bem das roupas - e daí o estudo dos têxteis, da tinturaria e da lavagem - como do fabrico dessas. Já na primeira disciplina aprendiam as funções do vestuário, os tipos físicos e a personalidade em relação ao vestuário, aos acessórios, ao uso

à conservação da máquina de costura, métodos e técnicas de costura, além de fazer as primeiras peças, como fronhas e vestidos de criança. Mas era na segunda disciplina que as alunas se aprofundariam na costura. Daí, a partir da unidade três, o estudo da seleção de modelo, de tecido, de traçado, de confecção de blusa (unidade 3), de saia (unidade 4), de calça comprida feminina (unidade 5) e de vestido (unidade 6). Esses estudos permitiriam à aluna fazer as roupas de sua família e dela mesma, aprendendo a escolher desde a roupa que lhe cairia melhor para seu porte físico e sua personalidade ao tecido

\footnotetext{
${ }^{4}$ A autora destaca o adestramento do corpo da mulher e sua necessária sujeição às normas ditadas pela Igreja Católica (1993, p. 124-154).
} 
mais propício àquela roupa. Ela aprende a vestir sua família e a se vestir bem para seu marido e para se apresentar em público. Vale lembrar que o "vestir-se bem" era de forma comportada que não envergonhasse o marido. Costurar para a família, além de ser uma economia para o bolso, era expressão da mulher prendada, companheira que supostamente adivinhava os desejos do marido, no imaginário social do amor romântico ou "amor ideal", no qual homens e mulheres tinham papéis definidos para uma feliz e duradoura vida conjugal.

Seguindo essa mesma ideia de se embelezar, a disciplina de Estética Pessoal era oferecida no $4^{\circ}$ período. No início dos estudos, a aluna deveria aprender o conceito de estética, além de sua relação com as áreas de saúde, nutrição e vestuário. A partir daí, estudaria sobre os cuidados e embelezamentos das unhas, da pele, do cabelo, da postura correta, além do problema do mercado produtor e consumidor de cosméticos.

Com a casa organizada, decorada e mobiliada, e ela mesma bela para o marido e para a sociedade, a mulher deveria saber cuidar dos filhos. Nesse sentido, torna-se importante para a mulher cuidar da saúde de sua família, conhecimento esse oferecido pelas disciplinas de Saúde I e Saúde II. Na primeira disciplina, a aluna deveria aprender sobre a educação sanitária, estudos da água como veículo de transmissão de doenças, a questão da limpeza pública, microbiologia, helmintologia e imunização para evitar que as doenças chegassem à sua família. Aprendia ainda os primeiros socorros no lar e na escola, para cuidar de possíveis acidentes. Já em Saúde II, os alunos aprenderiam socorros de urgência, como tratar de casos de envenenamento, traumatismos, hemorragias, ingestão de corpos estranhos pelas crianças e desmaios. Teriam ainda uma noção sobre administração de medicamentos, inclusive em forma de injeção, além de conhecer melhor os exames pré-nupciais, pré-natais e sobre o desenvolvimento da criança desde a gestão até a terceira infância. Dessa forma, a aluna teria os conhecimentos necessários para cuidar da saúde dos filhos, tanto de forma preventiva quanto de forma profilática.

Também no sentido de prevenir doenças e também de garantir o crescimento saudável das crianças, existiam as disciplinas Nutrição I e Nutrição II, oferecidas nos segundo e terceiro períodos respectivamente. Os currículos das duas disciplinas evidenciam o objetivo de capacitar as alunas a reconhecerem as propriedades de cada alimento e a prepararem um cardápio saudável e balanceado. Nesse sentido, a sétima unidade da disciplina de Nutrição I previa o estudo da alimentação correta para cada 
fase da vida. Da mesma forma, lê-se no conteúdo programático de Nutrição II, dentre outros pontos:

10 Reconhecimento dos fatores que influem no planejamento de um cardápio (hab. alimentares, condi. econ. , tabus, etc) Habilidade para elaborar cardápios nutritivos e dentro das possibilidades econômicas e com o aproveitamento de alimentos regionais.

11 habilidade para fazer compras dentro do orçamento e atendento (sic) às necessidades nutricionais das pessoas a que se destina a alimentação (UNIVERSIDADE CATÓLICA DE MINAS GERAIS, 1974; 1975; 1976; 1977).

Dessa forma, a aluna aprenderia que uma boa dieta deve se basear tanto em valores nutricionais quanto nos valores relativos ao orçamento familiar, reforçando, assim, os conhecimentos adquiridos com a disciplina de Economia Doméstica citada anteriormente.

Com a questão da saúde resolvida, a aluna estava apta a aprender a educar os filhos. Para isso, ela vinha se preparando desde o $1^{\circ}$ período, com a disciplina de Psicologia, Psicologia da Adolescência e da Aprendizagem I no $2^{\circ}$ período e Psicologia, Psicologia da Adolescência e da Aprendizagem II no $3^{\circ}$ período. A disciplina de Iniciação Filosofica I, Iniciação Filosófica II, Cultura Religiosa I e Cultura Religiosa II, obrigatórias a todos os cursos da Universidade, proporcionavam às alunas do curso de Educação para o Lar os conhecimentos necessários para que pudessem criar seus filhos sob preceitos éticos, morais e de valores cristãos.

Mas, ainda, eram oferecidos cursos específicos de licenciatura. Enquadram-se nessa classificação as disciplinas de Estrutura e Funcionamento do Ensino de $1^{\circ}$ grau no $2^{\circ}$ período e Estrutura e Funcionamento do Ensino de $2^{\circ}$ grau no $3^{\circ}$ período. Essas disciplinas traziam em seu conteúdo programático um pouco da história do ensino, discussão sobre o currículo, leis que regulam o ensino, a estrutura, o funcionamento da educação no Brasil e questões sobre matrículas, certificados e diplomas. Essas disciplinas eram complementadas por outras, como Princípios de didática e metodologia I, Seminários (Problemas Gerais da Educação e questões de Didática I) e Técnicas Áudio-Visuais no $4^{\circ}$ período e Princípios de Didática e Metodologia II, Seminários (Problemas Gerais da Educação e questões de Didática II) e Prática de Ensino (Estágio Supervisionado em Situação Real) no $5^{\circ}$ período. Além dessas disciplinas, a aluna teria ainda as disciplinas de Fundamentos de Orientação Educativa e Vocacional I e Fundamentos de Orientação Educativa e Vocacional II, através das quais ela aprenderia 
a ensinar os filhos/alunos a valorizar o trabalho como "plano de Deus a ser realizado" como consta na (Unidade 3 de Fundamentos de Orientação Educativa e Vocacional I) e ajudá-lo a escolher a profissão através do estudo das personalidades, das aptidões e dos interesses como está na (Unidade 2 de Fundamentos de Orientação Educativa e Vocacional II).

Essas últimas disciplinas citadas permitiam tanto que a aluna pudesse educar os seus filhos, ensinando-lhes valores e preparando-os para a vida e para o mercado de trabalho quanto dava-lhes uma formação para trabalhar no magistério - tanto que a habilitação concedida ao fim do curso era de Licenciatura de $1^{\circ}$ grau.

\section{A extinção do curso}

O curso deixa de ser oferecido no vestibular em 1977, apenas quatro anos após a sua criação. No Relatório de Atividades da UCMG, do ano de 1976, lê-se a deliberação do Conselho de Ensino e Pesquisa (CEP) de número 09 daquele ano: "Autoriza a reopção dos alunos de licenciatura do $1^{\circ}$ grau em Artes Práticas [...] em caráter excepcional, para qualquer curso das Áreas de Ciências Humanas ou de Ciências Sociais, sem observância dos preceitos estabelecidos na res. $\mathrm{N}^{\circ} 08 / 75$ - CEP”. 5

Embora não existam maiores explicações para o encerramento do curso, uma possível explicação foi a baixa procura pelo mesmo. Desde sua origem que o curso não conseguia preencher as 50 vagas oferecidas, tendo uma diminuição do número de alunos matriculados no decorrer da sua história, apresentando números como 34 inscritos no vestibular do segundo semestre de 1975, com a proporção de 0,68 candidatos por vaga. O número de matriculados é ainda inferior ao de inscritos, com 26 matriculados no $1^{\circ}$ semestre do mesmo ano, que teve 37 inscritos no vestibular. No segundo semestre de 1977, o curso contava apenas com 12 alunos matriculados ${ }^{6}$. Segundo Bassanezi, o desenvolvimento econômico da década de 1950 aumentou os níveis de escolaridade feminina e, na década seguinte, a proporção de homens para mulheres com curso superior, “que em 1950 era de 8,6 para 1,baixou, em 1960, para 5,6. O magistério era o curso mais procurado pelas moças, pois era próximo a maternidade e/ou proporcionava o prestígio do diploma. (BASSANEZI, 1997).

\footnotetext{
${ }^{5}$ Resolução criada pelo Conselho de Ensino e Pesquisa (CEP) que regulamentava a transferência interna.

${ }^{6}$ Dados obtidos nos Relatórios de Atividades da UCMG de 1975-1977.
} 
Os citados números do curso de Artes Práticas demonstram, acima de tudo, que o curso era incompatível com "a nova mulher" dos anos 1970/80 e com as novas demandas da sociedade a qual pretendia atender. Então por que a tentativa? Por que oferecer um curso em nível de terceiro grau para formação de donas de casa?

$\mathrm{Na}$ expectativa de tentar responder a essas perguntas lembramos que se tornava indispensável reverter o novo comportamento feminino, reafirmando o papel histórico das mulheres, desde a Colônia, como esposa abnegada, e mãe cuidadosa na criação da prole dentro da moral e dos valores cristãos, enfim, educada no modelo ditado pela Igreja Católica. Comprova essa afirmativa a Homilia aos Jovens, uma exortação feita pelo papa João Paulo II em sua visita a Belo Horizonte em $1^{\circ}$ de Julho de 1980. Criticando os movimentos que marcaram a geração de 1970, o Papa afirma:

\begin{abstract}
Meus amigos, vocês são também responsáveis pela conservação dos verdadeiros valores que sempre honraram o povo brasileiro. Não se deixem levar pela exasperação de sexo, que abala a autenticidade do amor humano e conduz á desagregação da família. "Não sabeis que vosso corpo é um templo e o Espírito Santo habita em vós?", escrevia São Paulo no texto que escutávamos.

Que as moças procurem encontrar o verdadeiro feminismo, a autêntica realização da mulher como pessoa humana, como parte integrante da família, e como parte da sociedade, numa participação consciente, segundo as suas características. (HOMILIA AOS JOVENS. JOÃO PAULO II, 1980).
\end{abstract}

Em outras palavras, o papa critica as mudanças de valores exigidos e vividos pela juventude da década de 1970, Reafirmando a importância da família nuclear e da realização da mulher, não em sua independência, mas como parte da família. Esse é o seu papel na sociedade. O fato da citada homilia ser a mensagem de abertura do Relatório de Atividades da UCMG, do ano de 1980, demonstra a concordância entre os valores da Igreja e da Universidade, enquanto instituição Católica.

Nesse sentido, a UCMG oferecia um curso que pretendia atender mais ao desejo das parcelas conservadoras da sociedade do que propriamente aos interesses dessa nova mulher que se constrói na década de 1970 e, por esse motivo, não encontra uma aceitação dessa parcela da sociedade que quer entrar na Universidade. A inserção das mulheres em cargos que antes eram exercidos apenas por homens citada por Bruschini e Amado (1998), demonstra seu desejo de ampliar sua área de atuação. O curso superior em Educação para o Lar não atende a esse desejo: antes, reafirma o seu lugar como dona de casa. 
Dessa forma, percebe-se que, embora o crescimento da área de Ciências Humanas dentro da UCMG seja visível (de 4.056 alunos em 1970, chega-se a 11.096 alunos matriculados nos cursos da Faculdade de Ciências Humanas no segundo semestre de 1977, segundo os Relatórios de Atividade), o curso de Artes Práticas não conseguiu acompanhar esse crescimento.

Concluindo, pode-se afirmar que o curso de Artes Práticas: Educação para o lar traz em si rupturas e permanências: é uma ruptura à medida que amplia a oportunidade que as mulheres tinham de ingressar nos níveis mais avançados da educação, diminuindo o privilégio masculino; ao mesmo tempo, é carregado de permanências ao reafirmar lugares definidos na sociedade para homem - o provedor da casa, para a mulher - aquela que cuida da casa e dos filhos. Assim, as mulheres mais preparadas desempenhariam melhor o papel que socialmente lhes cabia, reafirmando o lugar tradicional de procriadora, formadora da moral religiosa dos filhos e administradora competente do lar. De um lado, o curso era uma resposta às mudanças sociais do papel da mulher, possibilitando seu ingresso à educação superior, mas que mantinha, por outro, seu papel tradicional de subsidiar a ordem familiar.

Resta lembrar que o curso, provavelmente, voltava-se para um público específico: mulheres das classes dominantes e médias, ou seja, àquelas que teriam tempo disponível para estudar e, ainda atender às demandas constantes de filhos, marido e empregados domésticos. Preparadas tecnicamente e competentes administradoras do lar, essas mulheres se adequavam ao modelo da nova mulher da década de 1970: aquela que estuda, se informa, mas que não abandona sua função natural de mãe e esposa zelosa dos valores morais da família brasileira, “célula-mater da pátria”. Já as mulheres trabalhadoras e/ou operárias não teriam essa disponibilidade de tempo de preparo para o bom exercício das tarefas domésticas. Mas essas, provavelmente, não encarnariam essa nobre tarefa.

As décadas seguintes, de 1980, 1990 e o século XXI, trouxeram novos desafios especialmente para os homens. Esses, atualmente, competem no mercado de trabalho com mulheres cada vez mais preparadas e em número superior, a despeito da discriminação sofrida pelo "sexo frágil", que continua ganhando, em alguns casos, menor remuneração pela mesma tarefa executada por pessoas do sexo masculino. Rever esses papéis sociais tradicionalmente estabelecidos e impostos pela cultura dominante tem sido tarefa cotidiana de homens e mulheres cujas funções e atividades não cabem mais em estereótipos e nem em definições prévias. Estamos diante de "uma nova 
mulher", um "novo homem" "novas organizações familiares": eis um dos grandes desafios para nossa sociedade atual.

\author{
Course "Practical Arts: Education for the Home" \\ at the Catholic University of Minas Gerais: ruptures and permanency \\ in the relation women, family and education in the 1970s
}

\begin{abstract}
The 1970s was marked, in Brazil, by movements that sought to break with the "old morality," which led, among other things, greater sexual freedom, inclusion of women in sectors hitherto dominated by men, the schooling increasingly advanced levels of women and the legalization of divorce. In this context, the Catholic University of Minas Gerais (UCMG) created the course in Arts Practice: Education for the Home, which was aimed at providing an academic education that allows students to manage the home or become teachers. This article analyzes the course curriculum in order to identify which were the values which underlie it and plot the course of interests of society.
\end{abstract}

Key words: Continuities and ruptures; decade 1970s; Women; UCMG.

\title{
Referências
}

BARRETTO, Elba Siqueira de Sá. Tendências recentes do currículo do Ensino Fundamental no Brasil. In: BARRETTO, Elba Siqueira de Sá (Org.). Os currículos do ensino fundamental para as escolas brasileiras. São Paulo: Autores Associados, 1998.

BASSANEZI, Carla. "Mulheres dos Anos Dourados" In: PRIORE, Mary Del (Org.) História das Mulheres no Brasil. São Paulo: Contexto, 1997. p. 607-639.

BIASOLI-ALVES, Zélia Maria Mendes. Continuidades e Rupturas no papel da mulher brasileira no século XX. Psicologia: teoria e pesquisa, Ribeirão Preto, v. 16, n. 3, p.233239, set./dez. 2000.

BRASIL. Decreto-lei $N^{\circ}$ 464, de 11 de fevereiro de 1969. Estabelece normas complementares à Lei $\mathrm{n}^{\circ}$ 5.540, de 28 de novembro de 1968, e dá outras providências. Disponível em: <www.planalto.gov.br/ccivil_03/Decreto-Lei/1965-1988/D el0464.htm>. Acesso em: 25 Set 2009. 
BRAUDEL, Fernand. Escritos sobre a história. São Paulo: Perspectiva, 1978.

BRUSCHINI, Cristina; AMADO, Tina. Estudos sobre a mulher e a educação: algumas questões sobre o Magistério. Revista de Pesquisa, São Paulo, n 64, p. 4-13, fev. 1988.

COSTA, Ana Alice Alcântara. O movimento feminista no Brasil: dinâmicas de uma intervenção política. Gênero: Niterói, v. 5, n. 2, p. 9-35, jan./jun. 2005.

HABERT, Nadine. A década de 70: apogeu e crise da ditadura militar brasileira. 3. ed. São Paulo: Ática, 1996.

JOÃO PAULO II, Papa. Homilia aos Jovens. In: Relatório de atividades 1980. Belo Horizonte: FUMARC, 1981.

LOURO, Guacira Lopes. "Mulheres na sala de aula" In: Priore, Mary Del (Org.). História das mulheres no Brasil. São Paulo: Contexto, 1997.

DEL PRIORE, Mary. Ao sul do corpo: condição feminina, maternidades e mentalidades no Brasil colônia. Rio de Janeiro: José Olympio, 1993.

SILVA, Francisco Carlos Teixeira da. "A modernização autoritária: do golpe militar à redemocratização 1964-1984”. In: LINHARES, Maria Yedda (Org.). História Geral do Brasil. Rio de Janeiro: Campus, 1990.

UNIVERSIDADE CATÓLICA DE MINAS GERAIS. Artes Práticas - Educação para o Lar: Tabela Analítica do Curso para o ano de 1975. Belo Horizonte: UCMG, 1975.

UNIVERSIDADE CATÓLICA DE MINAS GERAIS. Relatório das atividades de 1973. Belo Horizonte: UCMG, 1974.

UNIVERSIDADE CATÓLICA DE MINAS GERAIS. Relatório das atividades de 1974. Belo Horizonte: UCMG, 1975.

UNIVERSIDADE CATÓLICA DE MINAS GERAIS. Artes Práticas - Educação para o Lar: Tabela Analítica do Curso para os anos de 1973/74. Belo Horizonte: UCMG, 1973.

UNIVERSIDADE CATÓLICA DE MINAS GERAIS. Artes Práticas - Educação para o Lar: Tabela Analítica do Curso para os anos de 1974/75/76. Belo Horizonte: UCMG, 1974.

UNIVERSIDADE CATÓLICA DE MINAS GERAIS. Artes Práticas - Educação para o Lar: Tabela Analítica do Curso para os anos de 1974/75/76. Belo Horizonte: UCMG, 1974.

UNIVERSIDADE CATÓLICA DE MINAS GERAIS. Relatório das atividades de 1975. Belo Horizonte: UCMG, 1975. 
UNIVERSIDADE CATÓLICA DE MINAS GERAIS. Relatório de atividades 1976. Belo Horizonte : [s.n.], 1977.

UNIVERSIDADE CATÓLICA DE MINAS GERAIS. Relatório 1977. Belo Horizonte: UCMG, 1978. 